\title{
Qualimetric-Competent Personnel Management at Aviation Engineering Enterprises
}

\author{
Anna Morozova \\ Department of Innovative Activity \\ Bryansk State Technical University \\ Bryansk, Russia \\ e-mail: niotiostu@gmail.com
}

\begin{abstract}
The solution of the applied problem in the numerical classification determination and identification of social objects realized on the basis of the model of the bi-subject assessment of objects with arbitrary nature is offered. On the basis of the general approach there is a developed model for the assessment of a professional competence level formation in a graduate of a university or vocational college. On the basis of graduate's progress level in subjects of an educational standard, the definition of basic quality metering and competence types of engineering personnel in an industrial enterprise and young experts' identification with them and also the selection of young specialists by an industrial enterprise manufacturing aircraft engineering products for vacant seat filling on the basis of their quality metering and competence comparison is offered. The results of investigations are obtained on the basis of principles of a system analysis, statistic and expert analytical methods and methods of simulation. The author has introduced concepts of the complete, standardized and clustered competence-diagram of a young specialist (a flat level model of the description of a young specialist's competence and clusters of competences). Quality metering and competence types of the engineering personnel of an engineering enterprise (in accordance with professional branch standards currently in force) are introduced by the author. Also concepts of generalized and shown indices of young specialist's competence allow applying a developed procedure under conditions of various kinds of engineering staff.
\end{abstract}

Keywords - identification, quality metering, selection, parameter-diagram

\section{INTRODUCTION}

The problem of vacant seat filling by competent specialists under conditions of current rapidly developing production is not only urgent, but also requires a prompt solution.

It is particularly difficult for decision-making in the situation when a vacant seat available in the engineering personnel may be filled by one or some candidates; at that, the young specialists' professional competences are shown indirectly in a university diploma or vocational college diploma.

On the whole, the problem of decision-making by a subject at the choice or any object selection on the basis of the opinion, which is already formed and fixed by other subject, is characteristic not only for the modern global society [16, 27], but also for different social groups (gender [23, 26], age [12, 13], professional [14, 20], national [10], discussion groups
$[11,15,22]$ and so on) during their formation, development and widening at the expense of new object obtaining.

It is possible to emphasize some basic reasons for the necessity to elaborate a method for quality metering $[5,6,7]$ selection of young specialists for modern industry (for aircraft engineering products manufacturing, in particular) on the basis of the model application for bi-subject estimation of objects with an arbitrary nature [17, 18]. The young specialist's competence characteristics are not available in the graduation diploma, but there is only progress in studies with credits (levels of student's advancements in subjects of training) [9, 24]. There are no methods for their comparison with the professional standards requirements to the competence of employees taking up a certain post. Besides, there is no analytical procedure developed allowing the comparison between each other; the levels of competence formation of certified graduates graduated from different colleges are in a similar training direction during the employment. Let us consider this problem from the position of quality metering with the application of a bi-subject estimation method of objects with different nature, at the heart of which there is estimation by one subject of the quality of characteristics formation in objects analyzed, the comparison of the estimations obtained with the system of other object parameters and further selection by the subject of one from the analyzed objects based on the own system of priorities [3, 4 19].

The simulator of quality metering determination and the general model of the comparison of objects with arbitrary nature are presented in works $[17,18]$.

\section{EASE OF USE}

Let objects (university graduates or vocational college graduates) be already assessed in an analytical system of one from the subjects (an educational standard in training direction of specialists used in an educational institution). In this case it is purposeful to transform an analytical parameter system in which the objects are already described into the system of parameters (requirements of professional standards for different specialists) of the second subject (industrial enterprise of aircraft engineering) participating in the quality analysis of characteristics formation of objects analyzed with 
the purpose of the further selection of one of them for a vacant seat filling.

A more complicated problem is when for the subject (an enterprise) has an own analytical system for a quality metering determination of objects with a certain nature (professional standards). It is necessary to carry out the comparison of several such objects (graduates) under conditions when the formation of their quality metering characteristics (competences) was carried out under different conditions (for example, during training at different colleges in the same specialist training direction). The most effective application of such approach is in a situation when the systems of object description are determined numerically that allows not only carrying out the transformation of parameter systems themselves, but also carrying out the normalization of scales used. Besides a manufacturing sphere, the practice of the application of such approach is rather wide: a field of commerce, business, policy, professional self-definition, hobby, taste preferences of clients and so on. [1, 2, 21, 25].

Let a graduate (an analyzed object) of a university or a vocational college from the position of the educational institution $\Omega$ be described on the basis of a realized educational standard by means of a set of the system of didactic units mastered by a graduate $D_{i}, i=\overline{1: n}$, combined into a set of training subjects $A_{j}, j=\overline{1: m}$, a mastery level of which is shown as grades reflecting the level of training advancement (LTA) in training subjects in a graduate's diploma. At that, a graduate's LTA in the whole of the aggregate of training subjects mastered by a graduate during a training process also shows latently a level of the competence formation of the graduate $B_{k}, k=\overline{1: l}$, presented in an educational standard. At that, each competence $B_{k}, k=\overline{1: l}$, is formed as an integrative information subspace defined by a level of the influence of a set of training subjects $A_{j}$, $j=\overline{1: m}$ (more thoroughly this process is considered in works $[13,18])$.

The level of the formation of the competence $B_{k}$ is influenced by not the whole of a set of training subjects $A_{j}$, $j=\overline{1: m}$, but by their certain subsystem $A_{j^{\prime} k}, j^{\prime}=\overline{1: m^{\prime}}$ and $k=\overline{1: l}$, where $m^{\prime} \leq m$. The components of the system of training subjects $A_{j^{\prime} k}, j^{\prime}=\overline{1: m^{\prime}}$ in description from the standpoint of the educational institution $\Omega$ of the $p$-th object obtain accordingly the values $s_{p j^{\prime}}$ (a level of training advancement in the training subject $A_{j^{\prime} k}$ ) and has the influence $\beta_{j^{\prime} k}$ upon the formation of the competence $B_{k}$. One may accept the level of its formation as a value:

$$
h_{p k}=\frac{\sum_{j^{\prime}=1}^{m^{\prime}} \beta_{j^{\prime} k} \cdot s_{p j^{\prime} k}}{m^{\prime}}
$$

in the description of an object (a graduate) from the standpoint of the subject $\Omega$ [1]. At the same time an educational institution may establish the threshold value $\beta_{k}^{\text {min }}$, at which, if the condition $\beta_{j^{\prime} k} \leq \beta_{k}^{\text {min }}$ is carried out, then the training subject $A_{j^{\prime}}$ has an insignificant influence upon the formation of the competence $B_{k}$ describing this object from the position of the subject $\Omega$. Hence, it is possible to admit conditionally that $\beta_{j^{\prime} k}=0$.

For the quality assessment of a competence system formation $B_{k}, k=\overline{1: l}$, of the university or vocational college graduate $\Omega$, it is expedient to determine some quality metering equations [7]. For example:

- $\quad H_{k}^{\min }$ - threshold level; it characterizes a minimum allowable level of the formation of this competence;

- $\quad H_{k}^{v}$ - advanced level; it characterizes conditionally a "mean" level of the formation in a graduate, the analyzed competence $B_{k}$;

- $H_{k}^{w}$ - high level; it characterizes conditionally a "high" level of the graduate's competence formation in a graduate $B_{k}$.

The values of the parameters $H_{k}^{\min }, H_{k}^{v}$ and $H_{k}^{w}$ are defined through expert-analytical methods by each educational institution $\Omega$ taking into account realization specificity in it of an educational standard in a specialists' training direction. Besides, in a number of cases it is possible to establish either only the values of threshold and high levels or to introduce one more additional level, for instance, a "advanced" one.

The set of values obtained $h_{p 1} ; h_{p 2} ; \ldots ; h_{p v} ; \ldots h_{p l}$ of the levels of graduate's competence formation $B_{k}, k=\overline{1: l}$, is an analytical matrix in the form of a vector-line characterizing quality of a competence system formation in a graduate from the position of an educational institution $\Omega$, from which one graduated, and formula (1) describes mathematically the level of graduate's competence formation on the basis of the model of quality metering determination of an object with arbitrary nature during its bi-subjective estimation.

The set of professional standards accepted for the introduction under conditions of modern industry $\Xi$ (including aircraft engineering) is based on the use of the competence cluster system $K_{r}, r=\overline{1: g}$.

Let, for example, in a vocational standard there be $g=6$ of competence clusters, then their system will become: $K_{1}, K_{2}, K_{3}, K_{4}, K_{5}, K_{6}$; as such system one may consider, for example, the system of competence clusters of the European system of engineering education: $K_{1}$ - "Knowledge and 
Comprehension", $K_{2}$ - "Engineering Analysis", $K_{3}$ "Engineering Designing", $K_{4}$ - "Engineering Practice", $K_{5}$ "Researches", $K_{6}$ - "Personal Skills". In such a way, in accepted educational standards, the system of competences $B_{k}, k=\overline{1: l}$, describing the system of competences of an object (a graduate) from the position of the educational institution $\Omega$ must be converted into a new system of competence clusters $K_{r}, r=\overline{1: g}$, describing an object (a young specialist) from the position of professional standard requirements currently in force under conditions of production $\Xi$.

At that, each competence $B_{k}$ takes different participation in the formation of each competence cluster $K_{r}, \quad r=\overline{1: g}$. Thereupon, it is expedient to introduce a system of share factors $\gamma_{k i}$, which characterize the level of the competence effect $B_{k}$ upon the formation of the competence cluster $K_{r}$, $r=\overline{1: g}$, so, it is advisable to use such values $\gamma_{k i}$, that $0 \leq \gamma_{k i} \leq 1$ and $\sum_{k=1}^{l} \gamma_{k i}=1$. The share factors $\gamma_{k i}$ can be defined through expert methods with the use of applied programs for the management decision-making support. Let the subset of the competences $B_{k^{\prime}}, k^{\prime}=\overline{1: l^{\prime}}$ participate in the formation of the competence cluster $K_{i}$. Then for the $p$-th object (a young specialist), the level of the competence formation $T_{p i}$ of the cluster $K_{i}$ can be assessed, for example, according to the mean value level among all available levels of the formation of the competences $B_{k^{\prime}} \subset\left\{B_{k}\right\}, k=\overline{1: l}$, $k^{\prime}=\overline{1: l^{\prime}}$, corrected according to the degree of the participation $\gamma_{k^{\prime} i}$ of the competence $B_{k^{\prime}}$ in the formation of the competence cluster $K_{i}, i=1, \ldots, 6$ and affecting the level of its formation. That is:

$$
T_{p i}=\frac{\sum_{k^{\prime}=1}^{l^{\prime}} \gamma_{k^{\prime} i} \cdot H_{p k^{\prime} i}}{k^{\prime}} .
$$

Besides, for every competence cluster $K_{i}, i=1, \ldots, 6$, one can also establish some levels of the formation $T_{i}^{\min }, T_{i}^{v}, T_{i}^{w}$. At the same time, technical potentialities, for example, of such software product as a system of decision-making support "Expert Decide", allow not only carrying out a stepwise assessment of the share factors $\beta_{j k}$ and $\gamma_{k i}$, but also estimating the share factor $\omega_{j i}$ of the influence of every component of the parameter system $A_{j}$, where $j=\overline{1: m}$, upon the system of the competence clusters $K_{i}$.

In this case, through expert methods, one obtains a vectorline consisting of the share factors $\omega_{j i}$ of the influence of each training subject $A_{j}$, where $j=\overline{1: m}$, upon the system of the competence clusters $K_{i}$. For example, having used the formula of the weighted mean:

$$
T_{p i}=\frac{\sum_{j=1}^{m} \omega_{j i} \cdot s_{p j}}{m},
$$

one can compute a level of the formation $T_{p i}$ of the competence cluster $K_{i}, i=1, \ldots, 6$ for the $p$-th object.

At modern enterprises of electrical industry, there are the most common engineering positions such as "engineer", "engineer-technologist", “design-engineer", "engineerresearcher", and so on. Each of these positions implies a certain system of priorities of the first, the second and the third class in the levels of competence cluster formation determined through an expert way. On basis of the results of research, one can form a matrix of the correspondence of a competence cluster priority structure at the quality metering typification of engineering personnel according to the position for a definite type of production (in our case - under consideration for manufacturing electrical products). The example of the fragment of such matrix of correspondence is shown in Table I.

TABLE I. A FRAGMENT OF THE MATRIX OF THE CONFORMITY OF THE PRIORITIES STRUCTURE OF COMPETENCE CLUSTERS BY QUALIMETRICCOMPETENCE TYPES FOR ENGINEERING AND TECHNICAL PERSONS ON POSITION IN CONDITIONS OF MANUFACTURING ELECTRICAL PRODUCTS (EXAMPLE)

\begin{tabular}{|l|c|c|c|}
\hline \multirow{2}{*}{$\begin{array}{c}\text { Type of engineering } \\
\text { position }\end{array}$} & \multicolumn{3}{|c|}{ Class priority } \\
\cline { 2 - 4 } & $K_{4}$ & $K_{6}$ & $K_{1}$ \\
\hline Engineer & $K_{2}$ & $K_{4}$ & $K_{1}$ \\
\hline Engineer-technologist & $K_{3}$ & $K_{4}$ & $K_{2}$ \\
\hline Design engineer & $K_{2}$ & $K_{3}$ & $K_{5}$ \\
\hline Engineer-programmer & $K_{5}$ & $K_{2}$ & $K_{3}$ \\
\hline Engineer-researcher & $\ldots$ & $\ldots$ & $\ldots$ \\
\hline$\cdots$ & & & \\
\hline
\end{tabular}

The specialist's cluster competence graph, created in the form of a petal-shaped diagram on the basis of the set of values $T_{p i}$ of the levels of the competence cluster formation $K_{i}, i=1, \ldots, 6$, will allow defining the most suitable position for a young specialist. So, for example, a variant of the competence graph shown in Fig. 1 allows making a conclusion that a young specialist should be employed best of all as a design engineer (presence of the priority of the 1 class in the competence cluster $K_{3}$, of the priority of the II class - in $K_{4}$, of the priority of the III class - in $K_{2}$ ). 


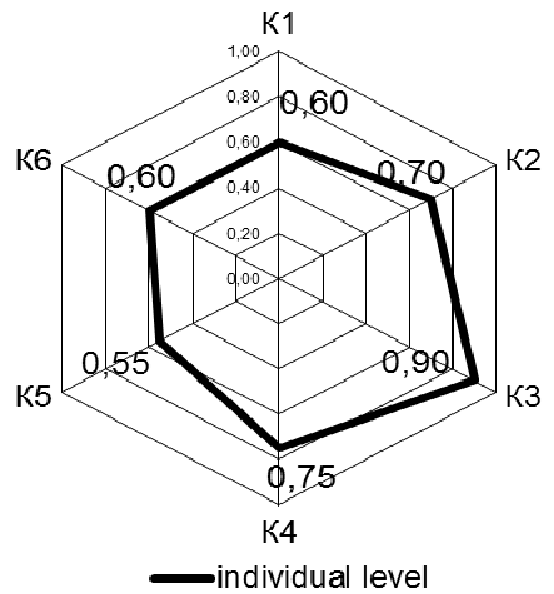

Fig. 1. Cluster competence - diagram of a specialist.

A specialist's cluster competence graph allows also solving a problem of defining a generalized index of specialist's competence $Z_{p}$ from the position of a subject (an industrial enterprise) $\Xi$ and obtained, on basis of the assessment by the subject $\Omega$ (an educational institution) of the system of specialist's competences formation.

The generalized index of the young specialist's competence $Z_{p}$ can be computed through the level of obtaining a mean value among all available individual levels of competence cluster formation, that is:

$$
Z_{p}=\frac{\sum_{i=1}^{6} T_{i}}{6} .
$$

If, for example, two graduates from the same university (both studied at the same university and trained on one curriculum) aspire to one vacant position, then the priority of one of them can be defined either according to the highest value of a generalized index of the young specialist's competence $Z_{p}$, or on the basis of the correspondence of the system of individual values to the levels of competence cluster formation in the structure of vacant position priorities in accordance with Table I (Fig. 2).

At the same time the individual level in the generalized index formation of the young specialist's competence $Z_{p}$, computed through the formula (4) reflects young specialist's characteristics without taking into account factors of the environment influence upon the subject $\Omega$ (an educational institution), which initially carried out the assessment of its graduate.

If two objects are compared with each other from the position of different subjects (universities), for example, $\Omega_{1}$ and $\Omega_{2}$, then the index $Z_{p}$ should be corrected by a rank factor of the university competitiveness $k_{v}$, which is defined through an expert method, for example, as a reciprocal to its rank in the country universities rating. In such a way, it is possible to suggest the mentioned index of young specialist's competence:

$$
\tilde{Z}_{p}=k_{v} \cdot Z_{p}
$$
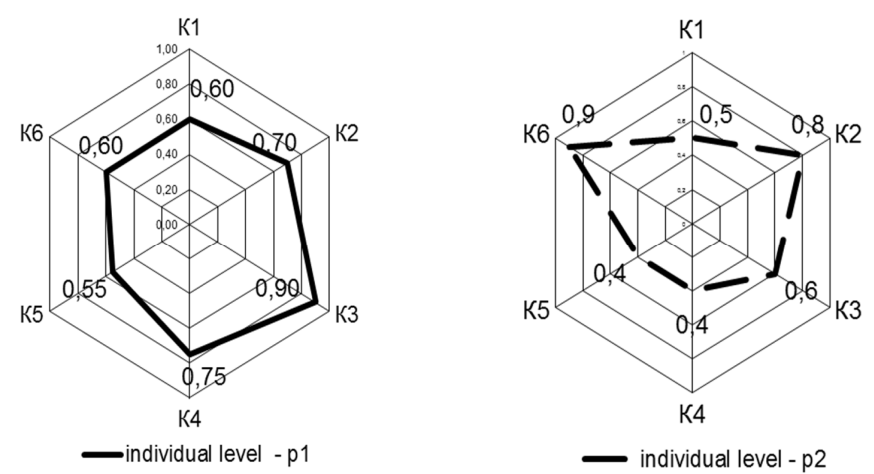

Fig. 2. The comparison of young specialists' cluster competence-diagrams and priority definition in the levels of their competence cluster.

Thereupon, for every young specialist comparable applying for a vacant position, the shown values $k_{v} \cdot T_{p 1}, \quad k_{v} \cdot T_{p 2}, \ldots, \quad k_{v} \cdot T_{p 6}$ can be computed concerning the levels of the cluster competence formation $K_{1}, K_{2}, K_{3}, K_{4}, K_{5}, K_{6}$.

In this case, a comparison of two young specialists, for example, $p_{1}$ and $p_{2}$, with the purpose of the definition of the aspirant meets the requirements for the vacant position available at an enterprise and can be carried out both on the basis of their shown indices of quality $Z_{p_{1}}$ and $Z_{p_{2}}$ (if their generalized comparison is carried out), and on the basis of the competence-diagrams shown of these objects (if the priority in the formation of a certain group of cluster competence $k_{v} \cdot T_{p 1}, \quad k_{v} \cdot T_{p 2}, \ldots, \quad k_{v} \cdot T_{p 6}$ in accordance with the data of Table I is analyzed). In Fig. 3 there is a presented example of the shown comparative cluster competence-diagram of two young specialists graduated from different universities.

It is obtained on the basis of transformed data, based on which there are formed competence-diagrams of two graduates presented in Fig. 2 with the values of factors of levels in the competence cluster formation at $k_{v 1}=0.87$ and $k_{v 2}=0.55$.

\section{CONCLUSIONS}

The application of the model of classification, determination and identification on the basis of a general model for bi-subject comparison of objects with arbitrary nature concerning young specialists working in manufacturing of aircraft products allows:

- estimating numerically a level of professional competence formation in a university or a vocational college graduate on the basis of graduate's progress levels on subjects of the educational standard; 


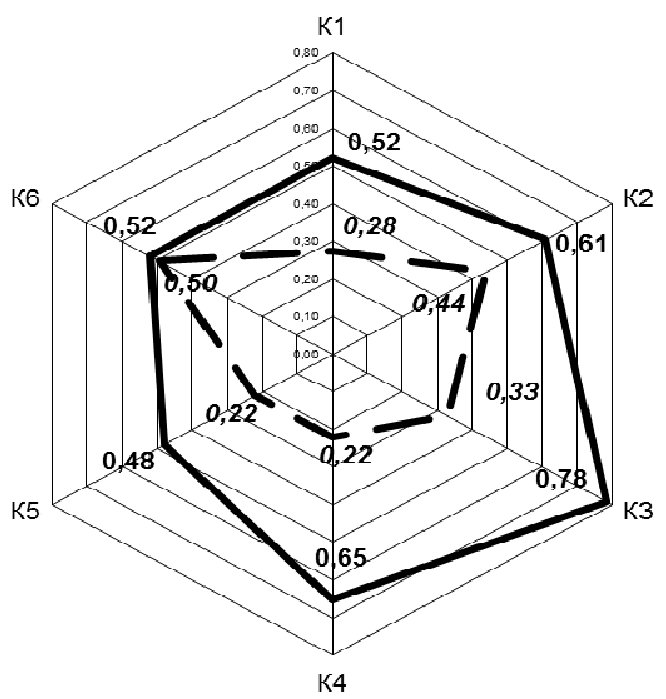

- individual level - p1

individual level - p2

Fig. 3. The comparative shown cluster compatence-diagram of two young specialists graduated from different universities.

- defining basic quality metering competence types of engineering personnel of an industrial enterprise;

- identifying young specialists participating in the vacancy filling of enterprise personnel with a certain quality metering competence type/types of engineering personnel of an industrial enterprise;

- $\quad$ carrying out a comparison of levels of professional competence formation in young specialists aspiring to vacant seat filling in accordance with professional standards in force at an enterprise manufacturing electric products.

The application of methods for the classification, determination and identification of social objects allows minimizing the subjectivity in the procedure of management decision-making during selection of young experts for vacant seats filling in modern (particularly science intensive) production, and also using applied software as a simulator for the development during the automation of these procedures $[8,21,24,25]$.

\section{References}

[1] Advanced engineering techniques, equipment and tools, 2015, pp. 378418.

[2] Advanced engineering techniques, equipment and tools, 2015, pp. 327351.

[3] K. Aswathappa, Human resource and personnel management, 2005.

[4] J. Atkinson, "Manpower strategies for flexible organisations", Personnel management, vol. 16, 8, pp. 28-31, 1984.

[5] G.G. Azgaldov, and A.V. Kostin, "Applied qualimetry: its origins, errors and misconceptions", Benchmarking: An International Journal, vol.18, 3, pp. 428-444, 2011.

[6] G.G. Azgaldov, The Foundations of Quality, 1982
[7] G. Azgaldov, A. Kostin, and A.P. Omiste, The ABC of Qualimetry. The Toolkit for Measuring Immeasurable, 2018.

[8] J. Cachay, and E. Abele, Developing competencies for continuous improvement processes on the shop floor through learning factoriesconceptual design and empirical validation, Procedia CiRP, vol. 3, pp. 2012, 638-643.

[9] L. Cannavacciuolo, et al., "An analytical framework based on AHP and activity-based costing to assess the value of competencies in production processes", International Journal of Production Research, vol. 50, 17, pp. 4877-4888, 2012

[10] W.M. Cole, "Does respect for human rights vary across 'civilizations'? A statistical reexamination", International Journal of Comparative Sociology, vol. 54, pp. 345-381, 2013.

[11] B.S. Greeberg, and R. Busselle, Audience dimensions of quality in situation comedies and action programmes, 1996, pp.169-196.

[12] O. Hochman, and N. Lewin-Epstein, "Determinants of early retirement preferences in Europe: The role of grandparenthood International", Journal of Comparative Sociology, February, vol. 54, pp. 29-47, 2013.

[13] M. Hooghe, and J. Oster, "The Rise of Engaged Citizenship: the Evolution of Citizenshop Norms among Adolescents in 21 Countries between 1999 and 2009", International Journal of Comparative Sociology, vol. 56, 1, pp. 29-52, 2015

[14] E. Kobayashi, H.R. Kerbo, and S.F. Sharp, "Differences in Individualistic and Collectivistic Tendencies among College Students in Japan and the United States International", Journal of Comparative Sociology, vol. 4, pp. 51-59, 2010.

[15] R. La Rose, "Perceived transmission quality assessment", Studies of Broadcasting, vol. 28, pp.77-119, 1992.

[16] J.W. Meyer, "Globalization: Theory and Trends International", Journal of Comparative Sociology, vol. 48, pp. 261-273, 2007.

[17] A. Morozova, "Formation of the system indicators analytic dependence during bisubject qualimetric evaluation of arbitrary objects", IOP Conference Series: Materials Science and Engineering, vol. 124, 2016, http://iopscience.iop.org/article/10.1088/1757-899X/124/1/012078.

[18] A. Morozova, "Mathematical model of bisubject qualimetric arbitrary objects evaluation", IOP Conference Series: Materials Science and Engineering, $\quad$ vol. 124,2016 , http://iopscience.iop.org/article/10.1088/1757-899X/124/1/012079.

[19] Jr H.F. O'Neil, and H.F. O'Neil, Workforce readiness: Competencies and assessment, 2014

[20] G. Passaretta and M. Triventi, "Work experience during higher education and post-graduation occupational outcomes: A comparative study on four European countries International", Journal of Comparative Sociology, 56, pp. 232-253, 2015.

[21] J. Rosas, P. Macedo, and L.M. Camarinha-Matos, "Extended competencies model for collaborative networks", Production Planning \& Control, vol. 22, 5-6, pp. 501-517, 2011.

[22] P. Rossler, Qualitat aus Transaktionaler Perspektive. Zur gemeinsamen Model-lierung von "User Quality" und "Sender Quality": Kriterien fur Onlinezeitungen, 2004, pp. $127-145$

23] A. Sundström, and D. Stockemer, "What determines women's political representation at the local level? A fine-grained analysis of the European regions International", Journal of Comparative Sociology, vol. 56, pp. 254-274, 2015.

[24] D. Ulrich, et al. Human resource competencies: An empirical assessment, Human resource management, vol. 3, 4, 1995, pp. 473-495.

[25] Jr.K.G. Veraldo, et al. "Assessment method of the competencies of industrial engineer in an interdisciplinary project," 12th International CDIO Conference, CDIO Project in Progress Contributions, Turku, Finland. - 2016, https://www.researchgate.net/publication/311678462.

[26] A. Sundström, and D. Stockemer, "What determines women's political representation at the local level? A fine-grained analysis of the European regionsInternational", Journal of Comparative Sociology, vol. 56, pp. 254-274, 2015.

[27] D. Ulrich, et al. Human resource competencies: An empirical assessment, Human resource management, vol. 3, 1995, pp. 473-495. 